\title{
Unilateral Diaphragmatic Paralysis Inhibits Postnatal Lung Growth in the Piglet
}

\author{
ELAINE M. SILLOS, DAVID F. DONNELLY, AND ANTHONY L. MANSELL \\ Department of Pediatrics, Babies Hospital and Columbia University College of Physicians and Surgeons, New \\ York, New York 10032
}

\begin{abstract}
To test the hypothesis that regional growth of lung parenchyma depends on regional distending pressure, left cervical phrenectomy was done in ten 2 -monthold piglets. The unilateral diaphragmatic paralysis reduced mean transpulmonary pressure in the left hemithorax from $5.5 \pm 1.0(\overline{\mathrm{x}} \pm \mathrm{SD})$ to $2.5 \pm 1.2 \mathrm{~cm} \mathrm{H}_{2} \mathrm{O}(p<0.01, n=$ 5). When five of the piglets were killed $48 \mathrm{~h}$ later, wet lung weight, total protein content, and nucleic acid content did not differ from values in the five sham operated controls. The five remaining phrenectomized piglets were compared to their five sham-operated controls 7 days after surgery. Wet weight of the left lung was reduced by $29 \%(p<0.01)$ and DNA content was reduced by $18 \%(p<0.05)$. Wet weight of the right lung, contralateral to the paralyzed hemidiaphragm, was reduced by $11 \%(p<0.05)$. At this time, body weight, bilateral transpulmonary pressure, and ratios of total protein/DNA and RNA/DNA in lung tissue did not differ from the sham-operated controls. These results suggest that regional growth of lung parenchyma by cell proliferation adjusted to changes in regional transpulmonary pressure caused by the unilateral phrenectomy. (Pediatr Res 23: 463-465, 1988)
\end{abstract}

\section{Abbreviation}

$\mathbf{P}_{\mathrm{tp}}$, transpulmonary pressure, alveolar pressure minus pleural pressure

Several determinants of postnatal lung growth have been suggested by experiments with compensatory lung growth after pneumonectomy or lung collapse (1). In particular, the compensatory response is inhibited by plombage of the thoracic cavity $(2,3)$, which indicates a determinant involving lung and chest wall mechanics. However, the possibility of a mechanical determinant is difficult to pursue further within the model of compensatory lung growth, which is complicated by loss of functioning lung tissue, ventilatory embarrassment and, in some cases, disturbance in body growth. Recently, Mansell et al. (4) altered regional, postnatal lung growth by producing unilateral diaphragmatic paralysis in cats and pigs. Because there was no loss of functioning lung tissue and no disturbance in body growth, unilateral diaphragmatic paralysis appeared to be a good model for studying mechanical factors affecting postnatal lung growth.

Herein we examine pulmonary distending pressure as a possible mechanical determinant of lung growth after unilateral diaphragmatic paralysis. Bilateral pleural balloons are used in the piglet, where unilateral phrenectomy can be done reliably by

Received September 21, 1987; accepted December 30, 1987.

Correspondence and reprint requests Anthony L. Mansell, M.D., Director, Pediatric Pulmonology, Rhode Island Hospital, Potter Building, Room 108, 593 Eddy Street, Providence, RI 02902.

Supported in part by National Heart, Lung, and Blood Institute Grant HL07421. E.M.S. was supported by a Pulmonary Training Grant from the Stony Wold-Herbert Fund. the cervical approach and where a relatively stiff mediastinum is expected to promote pressure differences between the two hemithoraces. In addition, unique data are presented for acute changes in bilateral transpulmonary pressure after unilateral cervical phrenectomy.

\section{METHODS}

Animals and surgical procedures. Twenty 8-wk-old female Yorkshire piglets, purchased from T. Morris, Inc., Reisterstown, MD, were anaesthetized using nitrous oxide and maintained with halothane. The piglets were restrained in the supine position with the left forelimb abducted to orient the brachial plexus at right angles to the phrenic nerve. A midline incision was made extending $6 \mathrm{~cm}$ below the hyoid cartilage, and a flap was extended laterally until the carotid sheath with the vagus nerve was located. The phrenic nerve was traced caudad until it coursed dorsal to the subclavian artery. The nerve was stimulated electrically and diaphragmatic contraction was verified visually. A 1-cm segment of the nerve was then excised in 10 experimental animals, whereas in the 10 controls neither electrical stimulation nor excision was performed. Experimental and control procedures were alternated.

In five of the experimental piglets and in their five controls, bilateral pleural pressures were measured before and $30 \mathrm{~min}$ after the surgical procedure. These 10 piglets were killed $48 \mathrm{~h}$ after the surgical procedure and their lungs were removed for measurements of wet weight, total protein, DNA, and RNA. In the other five experimental animals, and in their controls, bilateral pleural pressures were measured once only, 7 days after surgery. Immediately after the measurements of pleural pressure, these piglets were killed and their lungs were removed for measurements of total protein, DNA, and RNA.

Bilateral measurements of pleural pressure. A cutdown was made to the fourth rib one third of the distance from the sternum to the spine. A trochar ( $6 \mathrm{~mm}$ ID) containing a pleural balloon and sealed at the top by a pipette tip was placed in the incision just cranial to the rib. A purse string suture was then made in the pectoral muscles and fasciae to seal the incision externally. The trochar was then pushed into the pleural space and the balloon was threaded through the trochar, which was then withdrawn as the purse string suture was tightened. The pleural balloons were $4 \mathrm{~cm}$ long and constructed of latex fixed to polyethylene catheters. The balloon volume used was $0.1 \mathrm{ml}$ as determined by previous balloon compliance studies. After both pleural balloons were in place, pleural pressures were recorded with Statham P131C transducers which had been calibrated in parallel.

The measurements were done while the unintubated piglets were breathing spontaneously under light halothane anaesthesia. Pleural pressures were calculated at end expiration from a stable tracing of five tidal breaths. Results are expressed as $P_{t p}$, where alveolar pressure is assumed to be zero at end inspiration and at end expiration. Each signal was also meaned with regard to time and this measurement is expressed as mean $\mathrm{P}_{\mathrm{tp}}$. Measurements were always done with the piglets in supine, prone, and right and left lateral positions. 
The pleural balloons used for measurements before and immediately after phrenectomy were kept indwelling and reused 48 $\mathrm{h}$ later. However, artifacts then occurred in the measurements of pleural pressure. The balloons were found to be surrounded by and sealed into the visceral pleurae. For this reason, the tracings at $48 \mathrm{~h}$ were used only for measurements of respiratory frequency.

Lung tissue protein and nucleic acids. Animals were killed with an overdose of pentobarbital sodium. After incisions had been made in the atria for passive removal of blood, the lungs were removed rapidly, weighed, and frozen immediately in liquid nitrogen. The whole lung, including airways and blood vessels, was pulverized to a powder under liquid nitrogen with mortar and pestle. Each of the measurements was done using the entire lung. The powder was homogenized and DNA, RNA, and proteins were extracted serially by the Fleck and Monro method (5). Standards for DNA and RNA were prepared from calf thymus (6) and yeast (7), respectively. Lung tissue protein was determined by the method of Lowry et al. (8).

Statistical analysis. The Mann-Whitney (9) test was used for all comparisons between experimental animals and controls. To assess side to side differences caused by paralysis of the left hemidiaphragm, right/left ratios were compared between experimental animals and controls using the Mann-Whitney test. Changes within the experimental group caused by diaphragmatic paralysis were assessed by comparing values before and after phrenectomy using the paired $t$ test.

\section{RESULTS}

Bilateral transpulmonary pressures and respiratory frequency. Before phrenectomy under light anaesthesia in the supine position, respiratory frequency was $35 \pm 11(\tilde{\mathrm{x}} \pm \mathrm{SD}, n=10)$ breaths/ min. Transpulmonary pressures on the right and left sides did not differ significantly. The average of the two sides was $14.3 \pm$ $2.2 \mathrm{~cm} \mathrm{H}_{2} \mathrm{O}(n=10)$ at end inspiration and $-0.4 \pm 1.1 \mathrm{~cm} \mathrm{H}_{2} \mathrm{O}$ at end expiration. When the piglets were turned to lateral positions, right and left transpulmonary pressures differed significantly; i.e. end inspiratory pressures were $3.7 \pm 1.1 \mathrm{~cm} \mathrm{H}_{2} \mathrm{O}$ greater $(p<0.005)$ and end expiratory pressures were $4.8 \pm 1.1$ cm $\mathrm{H}_{2} \mathrm{O}$ greater $(p<0.005)$ at the top as compared to the bottom.

Thirty minutes after left cervical phrenectomy, respiratory frequency had not changed (37 \pm 11 breaths/min, $n=5)$. Outward movement of the abdomen during inspiration had decreased visually on the left, ipsilateral to the phrenectomy. Although the two tracings of transpulmonary pressure remained in phase, $\mathrm{P}_{\mathrm{tp}}$ on the left had decreased from 15.0 to $8.7 \mathrm{~cm} \mathrm{H}_{2} \mathrm{O}$ at end inspiration ( $p<0.002$ by paired $t$ test) and from 5.5 to $2.5 \mathrm{~cm} \mathrm{H}_{2} \mathrm{O}$ at the mean $(p<0.01$ by paired $t$ test). Values on the left were then reduced in the phrenectomized animals as compared to the controls at end inspiration $(p<0.005)$ and at the mean $(p<0.05)$ (Fig. 1). These differences were statistically significant only in the supine position. Measurements from the right hemithorax tended to change in the same direction as those from the left, as shown in Figure 1, but the experimental and control groups did not differ significantly in any position. Forty eight hours after phrenectomy, respiratory frequency still had not changed ( $35 \pm 13$ breaths/min) and did not differ from the control group. Right and left pleural pressure tracings continued to be in phase. Artifacts caused by encapsulation of the pleural balloons prevented measurements of $P_{t p}$ at $48 \mathrm{~h}$ (see "Methods").

Seven days after phrenectomy, respiratory frequency was a mean of $39 \pm 16$ breaths/min, which did not differ from the control group. Right and left pleural pressure tracings continued to be in phase. Transpulmonary pressures, as measured by newly placed balloons, did not differ in experimental and control groups.

Postmortem indices of lung growth. Body weight in the piglets who underwent phrenectomy did not differ from the controls at the time of surgery. Forty eight hours after surgery, the phrenectomized group had increased their body weights by a mean $3.1 \%$

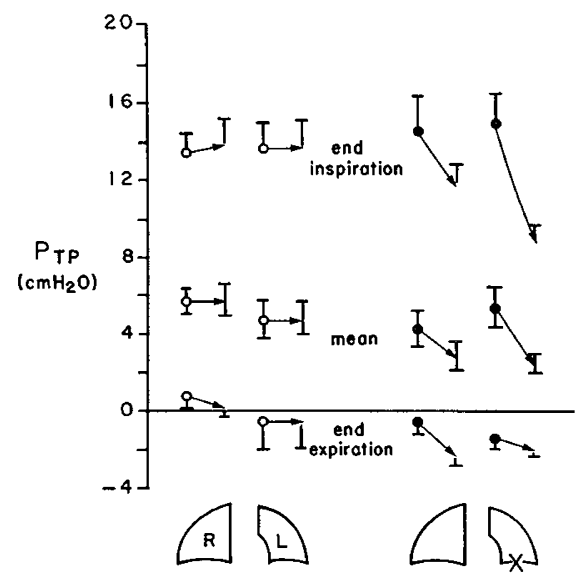

Fig. 1. Right and left transpulmonary pressures during tidal breathing in the two groups of 2-month-old piglets. Left cervical phrenectomy was done in the group represented by the closed circles; open circles represent the five controls. Results 30 min later are represented by arrows. Note that mean $(p<0.01)$ and end inspiratory $(p<0.002)$ transpulmonary pressure decreased on the left after phrenectomy. Values on the left were then significantly reduced in the phrenectomized animals as compared to the controls at end inspiration $(p<0.005)$ and at the mean $(p<$ $0.05)$.

as compared to $5.1 \%$ for their controls (NS). Seven days after surgery, the other phrenectomized group had increased their body weights by a mean of $21.9 \%$ as compared to $25.4 \%$ for their controls (NS). The two experimental groups did not differ from their controls for gain in body weight or for final body weight (Table 1).

Combined wet weight of both lungs did not correlate significantly with body weight in the 10 control 2 -month-old piglets, who ranged in body weight from 12.7 to $22.5 \mathrm{~kg}$.

There were no grossly visible areas of collapse in the lungs of experimental or control animals. In the phrenectomized piglets, the branches of the left phrenic nerve on the thoracic surface of the left hemidiaphragm appeared swollen. Hemidiaphragms that had been paralyzed appeared similar on gross inspection to those that had been intact.

In the pig, the four-lobed right lung is larger than the threelobed left lung (10). In our controls, right lungs were heavier (by a factor of 1.30) and contained more protein (1.36), DNA (1.28), and RNA (1.32) than did left lungs. The group studied $48 \mathrm{~h}$ after left phrenectomy did not differ from their controls for lung weight, total protein, DNA, or RNA (Table 1). The ratios total protein/DNA and RNA/DNA did not differ between right and left lungs or between experimental and control groups (Table 1).

The group studied 7 days after left phrenectomy had lighter right $(p<0.05)$ and left $(p<0.01)$ lungs compared to their controls (Fig. 2; Table 1). Reduction in lung weight was more pronounced on the left, ipsilateral to the phrenectomy, as shown by higher ratios of right/left lung weight in the phrenectomized group as compared to the controls (1.60 versus $1.27, p<0.01$ ). Content of DNA was less $(p<0.05)$ in the left lungs of the phrenectomized group as compared to the left lungs of the controls (Table 1). The ratios total protein/DNA and RNA/ DNA did not differ between right and left lungs or between experimental and control groups.

\section{DISCUSSION}

Lung growth is rapid in 2-month-old piglets; at this age, alveolar number may increase by $18 \%$ in $1 \mathrm{wk}$ (11). After $1 \mathrm{wk}$ of unilateral diaphragmatic paralysis, growth of both lungs was inhibited to the extent that total lung weight was reduced by $19 \%$ in the experimental animals. Growth inhibition was greater ipsilateral to the paralyzed hemidiaphragm than on the contralateral side, thus exaggerating the relative sizes of the four-lobed right lung and the three-lobed left lung. Wet weight, total protein 
Table 1. Growth indices $48 h$ and 7 days after left phrenectomy $(\bar{x} \pm S D ; n=5$ for each group)

\begin{tabular}{|c|c|c|c|c|c|c|c|c|c|c|}
\hline & & \multirow{2}{*}{$\begin{array}{l}\text { Body wt } \\
(\mathrm{kg})\end{array}$} & \multicolumn{2}{|c|}{ Wet lung wt (g) } & \multicolumn{2}{|c|}{ Protein (g) } & \multicolumn{2}{|c|}{ DNA (mg) } & \multicolumn{2}{|c|}{ RNA (mg) } \\
\hline & & & $\mathrm{L}$ & $\mathrm{R}$ & $\mathrm{L}$ & $\mathrm{R}$ & $\mathrm{L}$ & $\mathrm{R}$ & $\mathrm{L}$ & $\mathrm{R}$ \\
\hline \multirow[t]{4}{*}{$48 \mathrm{~h}$} & $\mathrm{E}$ & $19.7(19.1)^{*}$ & 119 & 165 & 7.1 & 9.8 & 519 & 717 & 317 & 456 \\
\hline & & $1.8(1.0)$ & 49 & 69 & 3.4 & 4.0 & 148 & 210 & 103 & 150 \\
\hline & $\mathrm{C}$ & $20.4(19.4)$ & 113 & 151 & 7.8 & 10.4 & 493 & 647 & 303 & 423 \\
\hline & & $1.6(2.1)$ & 30 & 31 & 2.7 & 3.4 & 54 & 63 & 20 & 45 \\
\hline \multirow[t]{4}{*}{7 days } & $\mathrm{E}$ & $13.0(10.7)$ & 76 & 1227 & 5.5 & 9.0 & 346 & 519 & 204 & 340 \\
\hline & & $3.2(1.4)$ & $\dagger\{8$ & $13\} \ddagger$ & 1.1 & 2.2 & $\ddagger\{49$ & 73 & 38 & 72 \\
\hline & & $14.3(11.4)$ & 108 & $137\}$ & 7.0 & 9.7 & 431 & 535 & 280 & 350 \\
\hline & & $1.8(1.3)$ & 12 & 6 & 0.7 & 0.9 & 38 & 90 & 60 & 69 \\
\hline
\end{tabular}

* Body wt before phrenectomy.

$\dagger p<0.01$.

$\ddagger p<0.05$.

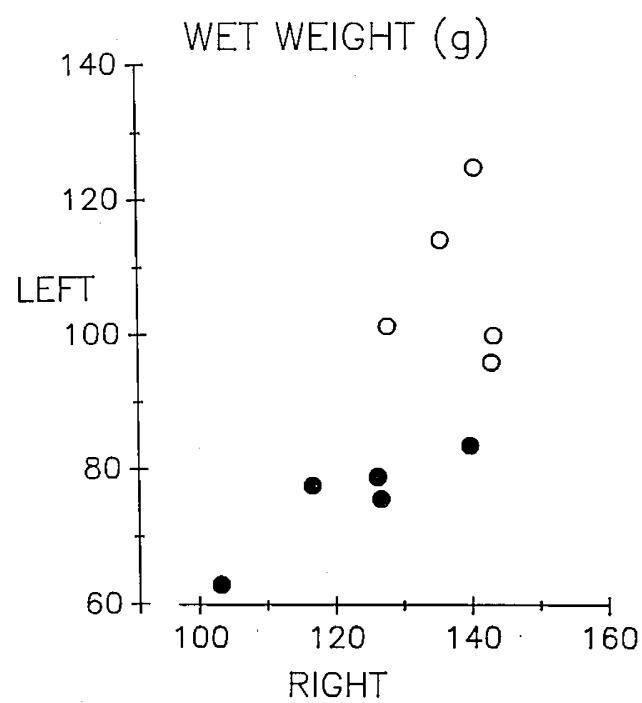

Fig. 2. Right and left lung weights 7 days after left phrenectomy. Open circles represent five controls; closed circles represent the five phrenectomized animals. Note that wet weight of left $(p<0.01)$ and right $(p<0.05)$ lungs was lower in phrenectomized animals as compared to the controls.

content, DNA, and RNA changed in proportion to one another, even though the reductions in protein and RNA were not statistically significant. Therefore, the inhibition in growth does not appear to have changed lung composition. Absolute quantities of DNA were reduced significantly, however, indicating that cell proliferation was inhibited with no change in mean cell size. By the same criteria, augmented lung growth after pneumonectomy (2) or lung collapse (3) occurs by increase in cell proliferation with no change in mean cell size.

Our results must be interpreted with attention to several limitations. First, because we did not examine the lungs by morphometry, no conclusions can be made about alveolar number or alveolar surface area per unit volume. However, our previous study of lung growth after unilateral diaphragmatic paralysis in cats showed that airspace volume per unit lung weight remained constant (4). Second, $\mathrm{P}_{\mathrm{tp}}$ in the midthorax and biochemical analysis of the whole lung must tend to conceal the most distinct regional effects of unilateral diaphragmatic paralysis, which are likely to be in the lower lobe close to the paralyzed hemidiaphragm (12). Third, increase in alveolar oxygen tension (13) or decrease in pulmonary blood flow (14) may inhibit postnatal lung growth. It is unlikely that unilateral diaphragmatic paralysis increased alveolar oxygen tension or decreased pulmonary blood flow bilaterally to explain the bilateral inhibition of parenchymal growth. However, it is still possible that changes in alveolar oxygen tension or changes in pulmonary or bronchial blood flow contributed to the changes in lung growth.

Unilateral diaphragmatic paralysis reduced ipsilateral transpulmonary pressure and inhibited ipsilateral growth of lung parenchyma in the piglet. However, the reduction in transpulmonary pressure was no longer detectable when the inhibition in lung growth was found, 7 days after phrenectomy. We interpret this pattern to mean that inhibition in lung growth occurred until the lungs "fit" a new thoracic shape and volume imposed by the phrenectomy. Transpulmonary pressure does not change substantially in the normal process of lung growth in humans, despite a 13-fold increase in lung volume from birth to age $6 \mathrm{yr}$ (15). In the piglets, compensatory hypertrophy of intercostal muscles (16) would be likely to modify thoracic shape and volume further if more time had been allowed to elapse after phrenectomy. Therefore, results after 7 days are unlikely to represent the final effects of left diaphragmatic paralysis on regional or total lung growth. Nevertheless, it is clear that regional growth of lung parenchyma by cell proliferation depends in part on regional distribution of respiratory muscle activity.

\section{REFERENCES}

1. Thurlbeck WM 1983 Postpneumonectomy compensatory lung growth. Am Rev Respir Dis 128:965-967

2. Cowan MJ, Crystal RG 1975 Lung growth after unilateral pneumonectomy: quantitation of collagen synthesis and content. Am Rev Respir Dis 111:257277

3. Inselman LS, Mellins RB, Brasel J 1977 Effect of lung collapse on compensatory growth. J Appl Physiol 43:27-31

4. Mansell AL, Rojas JV, Sillos EM, Stolar CJ, Collins MH, Rozovski SJ 1986 Diaphragmatic activity is a determinant of postnatal lung growth. J Appl Physiol 61:1098-1103

5. Fleck A, Monro HN 1962 The precision of ultra violet absorption measurements in the Schmidt-Tannhauser procedure for nucleic acid estimation. Biochim Biophys Acta 55:571-583

6. Ceriotti G 1955 Determination of nucleic acids in animal tissues. J Biol Chem 214:59-70

7. Crestfield AM, Smith KC, Allen FW 1955 The preparation and characterization of ribonucleic acids from yeast. J Biol Chem 216:185-193

8. Lowry OH, Rosebrough NJ, Farr AL, Randall RJ 1951 Protein measurement with the Folin phenol reagent. J Biol Chem 193:265-275

9. Zar JH 1974 Biostatistical Analysis. Prentice Hall Inc, Englewood Cliffs, NJ

10. Mount L, Ingram D 1971 The Pig as a Laboratory Animal. Academic Press, New York

11. Haworth SG, Hislop AA 1981 Adaptation of the pulmonary circulation to extra-uterine life in the pig and its relevance to the human infant. Cardiovasc Res 15:108-119

12. D'Angelo E, Sant'Ambrogio G, Agostoni E 1974 Effect of diaphragm activity and paralysis on distribution of pleural pressure. J Appl Physiol 37:311-315

13. Brody J 1975 Time course and stimuli to compensatory growth of the lung after pneumonectomy. J Clin Invest 56:897-904

14. Rabinovitch M, Herrera-deLeon V, Castaneda A, Reid L 1981 Growth and development of the pulmonary vascular bed in patients with Tetralogy of Fallot with and without pulmonary atresia. Circulation 64:1234-1249

15. Bryan A, Mansell A, Levison H 1977 Development of the mechanical properties of the respiratory system. In: Lenfant C (ed) Lung Biology in Health and Disease, Vol 6. Marcel Dekker, Inc., New York, pp 445-465

16. Sant'Ambrogio G, Miani A, Camporesi E 1970 Ventilatory response to hypercapnea in phrenectomized rabbits and cats. Respir Physiol 10:236-248 